\title{
Und wie geht man mit diesem Buch um?
}

Wie Sie vermutlich schon dem Inhaltsverzeichnis entnommen haben - falls es Ihre geschätzte Aufmerksamkeit fand - befassen wir uns mit einem Rundumschlag durch das deutsche Individual-Arbeitsrecht.

Am schönsten für das Buch ist es natürlich, wenn Sie es von Anfang bis Ende durchlesen - etwas, was Sie mit einer Gesetzessammlung übrigens nie tun sollten. Da fühlen alle Kapitel die gleiche Wertschätzung und sind glücklich.

Aber bitte, Sie haben dieses Werk zur Hand genommen. Also bestimmen Sie, wie Sie verfahren wollen. Vielleicht interessiert Sie ja ein ganz bestimmtes Kapitel, dann lesen Sie eben dieses. Sie sind da völlig frei.

Ich mache Ihnen da keine Vorschriften. Ich bin ja nicht der Gesetzgeber. 